\title{
A comparison of chemical mechanisms using tagged ozone production potential (TOPP) analysis
}

\author{
J. Coates and T. M. Butler \\ Institute for Advanced Sustainability Studies, Potsdam, Germany \\ Correspondence to: J. Coates (jane.coates@iass-potsdam.de)
}

Received: 10 April 2015 - Published in Atmos. Chem. Phys. Discuss.: 29 April 2015

Revised: 23 July 2015 - Accepted: 24 July 2015 - Published: 10 August 2015

\begin{abstract}
Ground-level ozone is a secondary pollutant produced photochemically from reactions of $\mathrm{NO}_{x}$ with peroxy radicals produced during volatile organic compound (VOC) degradation. Chemical transport models use simplified representations of this complex gas-phase chemistry to predict $\mathrm{O}_{3}$ levels and inform emission control strategies. Accurate representation of $\mathrm{O}_{3}$ production chemistry is vital for effective prediction. In this study, VOC degradation chemistry in simplified mechanisms is compared to that in the near-explicit Master Chemical Mechanism (MCM) using a box model and by "tagging" all organic degradation products over multi-day runs, thus calculating the tagged ozone production potential (TOPP) for a selection of VOCs representative of urban air masses. Simplified mechanisms that aggregate VOC degradation products instead of aggregating emitted VOCs produce comparable amounts of $\mathrm{O}_{3}$ from VOC degradation to the MCM. First-day TOPP values are similar across mechanisms for most VOCs, with larger discrepancies arising over the course of the model run. Aromatic and unsaturated aliphatic VOCs have the largest inter-mechanism differences on the first day, while alkanes show largest differences on the second day. Simplified mechanisms break VOCs down into smaller-sized degradation products on the first day faster than the MCM, impacting the total amount of $\mathrm{O}_{3}$ produced on subsequent days due to secondary chemistry.
\end{abstract}

\section{Introduction}

Ground-level ozone $\left(\mathrm{O}_{3}\right)$ is both an air pollutant and a climate forcer that is detrimental to human health and crop growth (Stevenson et al., 2013). $\mathrm{O}_{3}$ is produced from the reactions of volatile organic compounds (VOCs) and nitro- gen oxides $\left(\mathrm{NO}_{x}=\mathrm{NO}+\mathrm{NO}_{2}\right)$ in the presence of sunlight (Atkinson, 2000).

Background $\mathrm{O}_{3}$ concentrations have increased during the last several decades due to the increase of overall global anthropogenic emissions of $\mathrm{O}_{3}$ precursors (HTAP, 2010). Despite decreases in emissions of $\mathrm{O}_{3}$ precursors over Europe since 1990, EEA (2014) reports that $98 \%$ of Europe's urban population are exposed to levels exceeding the WHO air quality guideline of $100 \mu \mathrm{g} \mathrm{m}^{-3}$ over an $8 \mathrm{~h}$ mean. These exceedances result from local and regional $\mathrm{O}_{3}$ precursor gas emissions, their intercontinental transport and the non-linear relationship of $\mathrm{O}_{3}$ concentrations to $\mathrm{NO}_{x}$ and VOC levels (EEA, 2014).

Effective strategies for emission reductions rely on accurate predictions of $\mathrm{O}_{3}$ concentrations using chemical transport models (CTMs). These predictions require adequate representation of gas-phase chemistry in the chemical mechanism used by the CTM. For reasons of computational efficiency, the chemical mechanisms used by global and regional CTMs must be simpler than the nearly explicit mechanisms which can be used in box modelling studies. This study compares the impacts of different simplification approaches of chemical mechanisms on $\mathrm{O}_{3}$ production chemistry focusing on the role of VOC degradation products.

$$
\begin{aligned}
& \mathrm{NO}+\mathrm{O}_{3} \rightarrow \mathrm{NO}_{2}+\mathrm{O}_{2} \\
& \mathrm{NO}_{2}+h v \rightarrow \mathrm{NO}+\mathrm{O}\left({ }^{3} \mathrm{P}\right) \\
& \mathrm{O}_{2}+\mathrm{O}\left({ }^{3} \mathrm{P}\right)+\mathrm{M} \rightarrow \mathrm{O}_{3}+\mathrm{M}
\end{aligned}
$$

The photochemical cycle (Reactions R1-R3) rapidly produces and destroys $\mathrm{O}_{3}$. $\mathrm{NO}$ and $\mathrm{NO}_{2}$ reach a near-steady state via Reactions (R1) and (R2) which is disturbed in two cases. Firstly, via $\mathrm{O}_{3}$ removal (deposition or Reaction $\mathrm{R} 1$ during night-time and near large NO sources) and secondly, 
when $\mathrm{O}_{3}$ is produced through VOC- $\mathrm{NO}_{x}$ chemistry (Sillman, 1999).

VOCs $(\mathrm{RH})$ are mainly oxidised in the troposphere by the hydroxyl radical $(\mathrm{OH})$ forming peroxy radicals $\left(\mathrm{RO}_{2}\right)$ in the presence of $\mathrm{O}_{2}$. For example, Reaction (R4) describes the $\mathrm{OH}$ oxidation of alkanes proceeding though abstraction of an $\mathrm{H}$ from the alkane. In high- $\mathrm{NO}_{x}$ conditions, typical of urban environments, $\mathrm{RO}_{2}$ react with $\mathrm{NO}$ (Reaction $\mathrm{R} 5$ ) to form alkoxy radicals (RO), which react quickly with $\mathrm{O}_{2}$ (Reaction R6) producing a hydroperoxy radical $\left(\mathrm{HO}_{2}\right)$ and a carbonyl species $\left(\mathrm{R}^{\prime} \mathrm{CHO}\right)$. The secondary chemistry of these first-generation carbon-containing oxidation products is analogous to the sequence of Reactions (R4-R6), producing further $\mathrm{HO}_{2}$ and $\mathrm{RO}_{2}$ radicals. Subsequent-generation oxidation products can continue to react, producing $\mathrm{HO}_{2}$ and $\mathrm{RO}_{2}$ until they have been completely oxidised to $\mathrm{CO}_{2}$ and $\mathrm{H}_{2} \mathrm{O}$. Both $\mathrm{RO}_{2}$ and $\mathrm{HO}_{2}$ react with $\mathrm{NO}$ to produce $\mathrm{NO}_{2}$ (Reactions R5 and R7) leading to $\mathrm{O}_{3}$ production via Reactions (R2) and (R3). Thus, the amount of $\mathrm{O}_{3}$ produced from VOC degradation is related to the number of $\mathrm{NO}$ to $\mathrm{NO}_{2}$ conversions by $\mathrm{RO}_{2}$ and $\mathrm{HO}_{2}$ radicals formed during VOC degradation (Atkinson, 2000).

$$
\begin{aligned}
& \mathrm{RH}+\mathrm{OH}+\mathrm{O}_{2} \rightarrow \mathrm{RO}_{2}+\mathrm{H}_{2} \mathrm{O} \\
& \mathrm{RO}_{2}+\mathrm{NO} \rightarrow \mathrm{RO}+\mathrm{NO}_{2} \\
& \mathrm{RO}+\mathrm{O}_{2} \rightarrow \mathrm{R}^{\prime} \mathrm{CHO}+\mathrm{HO}_{2} \\
& \mathrm{HO}_{2}+\mathrm{NO} \rightarrow \mathrm{OH}+\mathrm{NO}_{2}
\end{aligned}
$$

Three atmospheric regimes with respect to $\mathrm{O}_{3}$ production can be defined (Jenkin and Clemitshaw, 2000). In the $\mathrm{NO}_{x}$ sensitive regime, VOC concentrations are much higher than those of $\mathrm{NO}_{x}$, and $\mathrm{O}_{3}$ production depends on $\mathrm{NO}_{x}$ concentrations. On the other hand, when $\mathrm{NO}_{x}$ concentrations are much higher than those of VOCs (VOC-sensitive regime), VOC concentrations determine the amount of $\mathrm{O}_{3}$ produced. Finally, the $\mathrm{NO}_{x}-\mathrm{VOC}$-sensitive regime produces maximal $\mathrm{O}_{3}$ and is controlled by both VOC and $\mathrm{NO}_{x}$ concentrations.

These atmospheric regimes remove radicals through distinct mechanisms (Kleinman, 1991). In the $\mathrm{NO}_{x}$-sensitive regime, radical concentrations are high relative to $\mathrm{NO}_{x}$ leading to radical removal by radical combination (Reaction R8) and bimolecular destruction (Reaction R9) (Kleinman, 1994).

$\mathrm{RO}_{2}+\mathrm{HO}_{2} \rightarrow \mathrm{ROOH}+\mathrm{O}_{2}$

$\mathrm{HO}_{2}+\mathrm{OH} \rightarrow \mathrm{H}_{2} \mathrm{O}+\mathrm{O}_{2}$

However, in the VOC-sensitive regime, radicals are removed by reacting with $\mathrm{NO}_{2}$ leading to nitric acid $\left(\mathrm{HNO}_{3}\right)$ (Reaction R10) and PAN species (Reaction R11).

$$
\begin{aligned}
& \mathrm{NO}_{2}+\mathrm{OH} \rightarrow \mathrm{HNO}_{3} \\
& \mathrm{RC}(\mathrm{O}) \mathrm{O}_{2}+\mathrm{NO}_{2} \rightarrow \mathrm{RC}(\mathrm{O}) \mathrm{O}_{2} \mathrm{NO}_{2}
\end{aligned}
$$

The $\mathrm{NO}_{x}-$ VOC-sensitive regime has no dominant radical removal mechanism as radical and $\mathrm{NO}_{x}$ amounts are compara- ble. This chemistry results in $\mathrm{O}_{3}$ concentrations being a nonlinear function of $\mathrm{NO}_{x}$ and $\mathrm{VOC}$ concentrations.

Individual VOCs impact $\mathrm{O}_{3}$ production differently through their diverse reaction rates and degradation pathways. These impacts can be quantified using ozone production potentials (OPPs), which can be calculated through incremental reactivity (IR) studies using photochemical models. In IR studies, VOC concentrations are changed by a known increment and the change in $\mathrm{O}_{3}$ production is compared to that of a standard VOC mixture. Examples of IR scales are the maximum incremental reactivity (MIR) and maximum ozone incremental reactivity (MOIR) scales in Carter (1994), as well as the photochemical ozone creation potential (POCP) scale of Derwent et al. (1996, 1998). The MIR, MOIR and POCP scales were calculated under different $\mathrm{NO}_{x}$ conditions, thus calculating OPPs in different atmospheric regimes.

Butler et al. (2011) calculate the maximum potential of a number of VOCs to produce $\mathrm{O}_{3}$ by using $\mathrm{NO}_{x}$ conditions inducing $\mathrm{NO}_{x}-\mathrm{VOC}$-sensitive chemistry over multi-day scenarios using a "tagging" approach - the tagged ozone production potential (TOPP). Tagging involves labelling all organic degradation products produced during VOC degradation with the name of the emitted VOCs. Tagging enables the attribution of $\mathrm{O}_{3}$ production from VOC degradation products back to the emitted VOCs, thus providing detailed insight into VOC degradation chemistry. Butler et al. (2011), using a near-explicit chemical mechanism, showed that some VOCs, such as alkanes, produce maximum $\mathrm{O}_{3}$ on the second day of the model run; in contrast to unsaturated aliphatic and aromatic VOCs which produce maximum $\mathrm{O}_{3}$ on the first day. In this study, the tagging approach of Butler et al. (2011) is applied to several chemical mechanisms of reduced complexity, using conditions of maximum $\mathrm{O}_{3}$ production $\left(\mathrm{NO}_{x}-\right.$ VOC-sensitive regime), to compare the effects of different representations of VOC degradation chemistry on $\mathrm{O}_{3}$ production in the different chemical mechanisms.

A near-explicit mechanism, such as the Master Chemical Mechanism (MCM) (Jenkin et al., 2003; Saunders et al., 2003; Bloss et al., 2005), includes detailed degradation chemistry making the MCM ideal as a reference for comparing chemical mechanisms. Reduced mechanisms generally take two approaches to simplifying the representation of VOC degradation chemistry: lumped-structure approaches and lumped-molecule approaches (Dodge, 2000).

Lumped-structure mechanisms speciate VOCs by the carbon bonds of the emitted VOCs (e.g. the Carbon Bond mechanisms, CBM-IV (Gery et al., 1989) and CB05 (Yarwood et al., 2005)). Lumped-molecule mechanisms represent VOCs explicitly or by aggregating (lumping) many VOCs into a single mechanism species. Mechanism species may lump VOCs by functionality (MOdel for Ozone and Related chemical Tracers, MOZART-4, Emmons et al., 2010) or OH reactivity (Regional Acid Deposition Model, RADM2 (Stockwell et al., 1990), Regional Atmospheric Chemistry 
Mechanism, RACM (Stockwell et al., 1997) and RACM2 (Goliff et al., 2013)). The Common Representative Intermediates mechanism (CRI) lumps the degradation products of VOCs rather than the emitted VOCs (Jenkin et al., 2008).

Many comparison studies of chemical mechanisms consider modelled time series of $\mathrm{O}_{3}$ concentrations over varying VOC and $\mathrm{NO}_{x}$ concentrations. Examples are Dunker et al. (1984), Kuhn et al. (1998) and Emmerson and Evans (2009). The largest discrepancies between the time series of $\mathrm{O}_{3}$ concentrations in different mechanisms from these studies arise when modelling urban rather than rural conditions and are attributed to the treatment of radical production, organic nitrate and night-time chemistry. Emmerson and Evans (2009) also compare the inorganic gas-phase chemistry of different chemical mechanisms; differences in inorganic chemistry arise from inconsistencies between IUPAC and JPL reaction rate constants.

Mechanisms have also been compared using OPP scales. OPPs are a useful comparison tool as they relate $\mathrm{O}_{3}$ production to a single value. Derwent et al. (2010) compared the near-explicit MCM v3.1 and SAPRC-07 mechanisms using first-day POCP values calculated under VOC-sensitive conditions. The POCP values were comparable between the mechanisms. Butler et al. (2011) compared first-day TOPP values to the corresponding published MIR, MOIR and POCP values. TOPP values were most comparable to MOIR and POCP values due to the similarity of the chemical regimes used in their calculation.

In this study, we compare TOPP values of VOCs using a number of mechanisms to those calculated with the MCM v3.2, under standardised conditions which maximise $\mathrm{O}_{3}$ production. Differences in $\mathrm{O}_{3}$ production are explained by the differing treatments of secondary VOC degradation in these mechanisms.

\section{Methodology}

\subsection{Chemical mechanisms}

The nine chemical mechanisms compared in this study are outlined in Table 1 with a brief summary below. We used a subset of each chemical mechanism containing all the reactions needed to fully describe the degradation of the VOCs in Table 2. The reduced mechanisms in this study were chosen as they are commonly used in 3-D models and apply different approaches to representing secondary VOC chemistry. The recent review by Baklanov et al. (2014) shows that each chemical mechanism used in this study are actively used by modelling groups.

The MCM (Jenkin et al., 1997, 2003; Saunders et al., 2003; Bloss et al., 2005; Rickard et al., 2015) is a nearexplicit mechanism which describes the degradation of 125 primary VOCs. The MCM v3.2 is the reference mechanism in this study due to its level of detail (16 349 organic reac- tions). Despite this level of detail, the MCM had difficulties in reproducing the results of chamber study experiments involving aromatic VOCs (Bloss et al., 2005).

The CRI (Jenkin et al., 2008) is a reduced chemical mechanism with 1145 organic reactions describing the oxidation of the same primary VOCs as the MCM v3.1 (12 691 organic reactions). VOC degradation in the CRI is simplified by lumping the degradation products of many VOCs into mechanism species whose overall $\mathrm{O}_{3}$ production reflects that of the MCM v3.1. The CRI v2 is available in more than one reduced variant, described in Watson et al. (2008). We used a subset of the full version of the CRI v2 (http://mcm.leeds.ac.uk/CRI). Differences in $\mathrm{O}_{3}$ production between the CRI v2 and MCM v3.2 may be due to changes in the MCM versions rather than the CRI reduction techniques, hence the MCM v3.1 is also included in this study.

MOZART-4 represents global tropospheric and stratospheric chemistry (Emmons et al., 2010). Explicit species exist for methane, ethane, propane, ethene, propene, isoprene and $\alpha$-pinene. All other VOCs are represented by lumped species determined by the functionality of the VOCs. Tropospheric chemistry is described by 145 organic reactions in MOZART-4.

RADM2 (Stockwell et al., 1990) describes regional-scale atmospheric chemistry using 145 organic reactions with explicit species representing methane, ethane, ethene and isoprene. All other VOCs are assigned to lumped species based on $\mathrm{OH}$ reactivity and molecular weight. RADM2 was updated to RACM (Stockwell et al., 1997) with more explicit and lumped species representing VOCs as well as revised chemistry (193 organic reactions). RACM2 is the updated RACM version (Goliff et al., 2013) with substantial updates to the chemistry, including more lumped and explicit species representing emitted VOCs (315 organic reactions).

CBM-IV (Gery et al., 1989) uses 46 organic reactions to simulate polluted urban conditions and represents ethene, formaldehyde and isoprene explicitly while all other emitted VOCs are lumped by their carbon bond types. All primary VOCs were assigned to lumped species in CBM-IV as described in Hogo and Gery (1989). For example, the mechanism species PAR represents the $\mathrm{C}-\mathrm{C}$ bond. Pentane, having five carbon atoms, is represented as 5 PAR. A pentane mixing ratio of $1200 \mathrm{pptv}$ is assigned to $6000(=1200 \times 5)$ pptv of PAR in CBM-IV. CBM-IV was updated to CB05 (Yarwood et al., 2005) by including further explicit species representing methane, ethane and acetaldehyde, and has 99 organic reactions. Other updates include revised allocation of primary VOCs and updated rate constants.

\subsection{Model set-up}

The modelling approach and set-up follows the original TOPP study of Butler et al. (2011). The approach is summarised here; further details can be found in the Supplement and in Butler et al. (2011). We use the MECCA box model, 
Table 1. The chemical mechanisms used in the study are shown here. MCM v3.2 is the reference mechanism. The number of organic species and reactions needed to fully oxidise the VOCs in Table 2 for each mechanism are also included.

\begin{tabular}{|c|c|c|c|c|c|}
\hline $\begin{array}{l}\text { Chemical } \\
\text { mechanism }\end{array}$ & $\begin{array}{r}\text { Number of } \\
\text { organic species }\end{array}$ & $\begin{array}{r}\text { Number of } \\
\text { organic reactions }\end{array}$ & $\begin{array}{l}\text { Type of } \\
\text { lumping }\end{array}$ & Reference & $\begin{array}{l}\text { Recent } \\
\text { study }\end{array}$ \\
\hline MCM v3.2 & 1884 & 5621 & No lumping & Rickard et al. (2015) & Koss et al. (2015) \\
\hline MCM v3.1 & 1677 & 4862 & No lumping & $\begin{array}{l}\text { Jenkin et al. (1997) } \\
\text { Saunders et al. (2003) } \\
\text { Jenkin et al. (2003) } \\
\text { Bloss et al. (2005) }\end{array}$ & Lidster et al. (2014) \\
\hline CRI v2 & 189 & 559 & Lumped intermediates & Jenkin et al. (2008) & Derwent et al. (2015) \\
\hline MOZART-4 & 61 & 135 & Lumped molecule & Emmons et al. (2010) & Hou et al. (2015) \\
\hline RADM2 & 42 & 105 & Lumped molecule & Stockwell et al. (1990) & Li et al. (2014) \\
\hline RACM & 51 & 152 & Lumped molecule & Stockwell et al. (1997) & Ahmadov et al. (2015) \\
\hline RACM2 & 92 & 244 & Lumped molecule & Goliff et al. (2013) & Goliff et. al. (2015) \\
\hline CBM-IV & 19 & 47 & Lumped structure & Gery et al. (1989) & Foster et al. (2014) \\
\hline CB05 & 33 & 86 & Lumped structure & Yarwood et al. (2005) & Dunker et al. (2015) \\
\hline
\end{tabular}

originally described by Sander et al. (2005), and as subsequently modified by Butler et al. (2011) to include MCM chemistry. In this study, the model is run under conditions representative of $34^{\circ} \mathrm{N}$ at the equinox (broadly representative of the city of Los Angeles, USA).

Maximum $\mathrm{O}_{3}$ production is achieved in each model run by balancing the chemical source of radicals and $\mathrm{NO}_{x}$ at each time step by emitting the appropriate amount of NO. These $\mathrm{NO}_{x}$ conditions induce $\mathrm{NO}_{x}-\mathrm{VOC}$-sensitive chemistry. Ambient $\mathrm{NO}_{x}$ conditions are not required as this study calculates the maximum potential of VOCs to produce $\mathrm{O}_{3}$. Future work should verify the extent to which the maximum potential of VOCs to produce $\mathrm{O}_{3}$ is reached under ambient $\mathrm{NO}_{x}$ conditions.

VOCs typical of Los Angeles and their initial mixing ratios are taken from Baker et al. (2008), listed in Table 2. Following Butler et al. (2011), the associated emissions required to keep the initial mixing ratios of each VOC constant until noon of the first day were determined for the MCM v3.2. These emissions are subsequently used for each mechanism, ensuring the amount of each VOC emitted was the same in every model run. Methane $\left(\mathrm{CH}_{4}\right)$ was fixed at $1.8 \mathrm{ppmv}$ while $\mathrm{CO}$ and $\mathrm{O}_{3}$ were initialised at 200 and $40 \mathrm{ppbv}$ and then allowed to evolve freely.

The VOCs used in this study are assigned to mechanism species following the recommendations from the literature of each mechanism (Table 1), the representation of each VOC in the mechanisms is found in Table 2. Emissions of lumped species are weighted by the carbon number of the mechanism species ensuring the total amount of emitted reactive carbon was the same in each model run.

The MECCA box model is based upon the Kinetic PreProcessor (KPP) (Damian et al., 2002). Hence, all chemical mechanisms were adapted into modularised KPP format. The inorganic gas-phase chemistry described in the MCM v3.2 was used in each run to remove any differences between treatments of inorganic chemistry in each mechanism. Thus, differences between the $\mathrm{O}_{3}$ produced by the mechanisms are due to the treatment of organic degradation chemistry.

The MCM v3.2 approach to photolysis, dry deposition of VOC oxidation intermediates and $\mathrm{RO}_{2}-\mathrm{RO}_{2}$ reactions was used for each mechanism; details of these adaptations can be found in the Supplement. Some mechanisms include reactions which are only important in the stratosphere or free troposphere. For example, PAN photolysis is only important in the free troposphere (Harwood et al., 2003) and was removed from MOZART-4, RACM2 and CB05 for the purpose of the study, as this study considers processes occurring within the planetary boundary layer.

\subsection{Tagged ozone production potential (TOPP)}

This section summarises the tagging approach described in Butler et al. (2011) which is applied in this study.

\subsection{1 $O_{x}$ family and tagging approach}

$\mathrm{O}_{3}$ production and loss is dominated by rapid photochemical cycles, such as Reactions (R1)-(R3). The effects of rapid production and loss cycles can be removed by using chemical families that include rapidly inter-converting species. In this study, we define the $\mathrm{O}_{x}$ family to include $\mathrm{O}_{3}, \mathrm{O}\left({ }^{3} \mathrm{P}\right), \mathrm{O}\left({ }^{1} \mathrm{D}\right)$, $\mathrm{NO}_{2}$ and other species involved in fast cycling with $\mathrm{NO}_{2}$, such as $\mathrm{HO}_{2} \mathrm{NO}_{2}$ and PAN species. Thus, production of $\mathrm{O}_{x}$ can be used as a proxy for production of $\mathrm{O}_{3}$.

The tagging approach follows the degradation of emitted VOCs through all possible pathways by labelling every organic degradation product with the name of the emitted VOCs. Thus, each emitted VOC effectively has its own set of degradation reactions. Butler et al. (2011) showed that $\mathrm{O}_{x}$ production can be attributed to the VOCs by following the tags of each VOC. 
Table 2. Non-methane volatile organic compounds (NMVOCs) present in Los Angeles. Mixing ratios are taken from Baker et al. (2008) and their representation in each chemical mechanism. The representation of the VOCs in each mechanism is based upon the recommendations of the literature for each mechanism (Table 1).

\begin{tabular}{|c|c|c|c|c|c|c|c|c|}
\hline NMVOCs & $\begin{array}{l}\text { Mixing } \\
\text { ratio (pptv) }\end{array}$ & $\begin{array}{l}\text { MCM v3.1, v3.2, } \\
\text { CRI v2 }\end{array}$ & MOZART-4 & RADM2 & RACM & RACM2 & CBM-IV & CB05 \\
\hline \multicolumn{9}{|c|}{ Alkanes } \\
\hline Ethane & 6610 & $\mathrm{C} 2 \mathrm{H} 6$ & $\mathrm{C} 2 \mathrm{H} 6$ & ETH & ETH & ETH & 0.4 PAR & ETHA \\
\hline Propane & 6050 & $\mathrm{C} 3 \mathrm{H} 8$ & $\mathrm{C} 3 \mathrm{H} 8$ & $\mathrm{HC} 3$ & $\mathrm{HC} 3$ & $\mathrm{HC} 3$ & 1.5 PAR & 1.5 PAR \\
\hline Butane & 2340 & $\mathrm{NC} 4 \mathrm{H} 10$ & BIGALK & $\mathrm{HC} 3$ & $\mathrm{HC} 3$ & $\mathrm{HC} 3$ & 4 PAR & 4 PAR \\
\hline 2-Methylpropane & 1240 & IC4H10 & BIGALK & $\mathrm{HC} 3$ & $\mathrm{HC} 3$ & $\mathrm{HC} 3$ & 4 PAR & 4 PAR \\
\hline Pentane & 1200 & $\mathrm{NC} 5 \mathrm{H} 12$ & BIGALK & HC5 & HC5 & HC5 & 5 PAR & 5 PAR \\
\hline 2-Methylbutane & 2790 & IC5H12 & BIGALK & HC5 & HC5 & HC5 & 5 PAR & 5 PAR \\
\hline Hexane & 390 & NC6H14 & BIGALK & HC5 & $\mathrm{HC} 5$ & HC5 & 6 PAR & 6 PAR \\
\hline Heptane & 160 & NC7H16 & BIGALK & HC5 & HC5 & HC5 & 7 PAR & 7 PAR \\
\hline Octane & 80 & NC8H18 & BIGALK & $\mathrm{HC} 8$ & $\mathrm{HC} 8$ & $\mathrm{HC} 8$ & 8 PAR & 8 PAR \\
\hline \multicolumn{9}{|c|}{ Alkenes } \\
\hline Ethene & 2430 & $\mathrm{C} 2 \mathrm{H} 4$ & $\mathrm{C} 2 \mathrm{H} 4$ & OL2 & ETE & ETE & ETH & ETH \\
\hline Propene & 490 & $\mathrm{C} 3 \mathrm{H} 6$ & C3H6 & OLT & OLT & OLT & $\mathrm{OLE}+\mathrm{PAR}$ & $\mathrm{OLE}+\mathrm{PAR}$ \\
\hline Butene & 65 & BUT1ENE & BIGENE & OLT & OLT & OLT & $\mathrm{OLE}+2$ PAR & $\mathrm{OLE}+2 \mathrm{PAR}$ \\
\hline 2-Methylpropene & 130 & MEPROPENE & BIGENE & OLI & OLI & OLI & $\begin{array}{l}\mathrm{PAR}+\mathrm{FORM} \\
+\mathrm{ALD} 2\end{array}$ & $\begin{array}{l}\text { FORM }+ \\
3 \text { PAR }\end{array}$ \\
\hline Isoprene & 270 & $\mathrm{C} 5 \mathrm{H} 8$ & ISOP & ISO & ISO & ISO & ISOP & ISOP \\
\hline \multicolumn{9}{|c|}{ Aromatics } \\
\hline Benzene & 480 & BENZENE & TOLUENE & TOL & TOL & $\mathrm{BEN}$ & PAR & PAR \\
\hline Toluene & 1380 & TOLUENE & TOLUENE & TOL & TOL & TOL & TOL & TOL \\
\hline m-Xylene & 410 & MXYL & TOLUENE & XYL & XYL & XYM & XYL & XYL \\
\hline p-Xylene & 210 & PXYL & TOLUENE & XYL & XYL & XYP & XYL & XYL \\
\hline o-Xylene & 200 & OXYL & TOLUENE & XYL & XYL & XYO & XYL & XYL \\
\hline Ethylbenzene & 210 & EBENZ & TOLUENE & TOL & TOL & TOL & $\mathrm{TOL}+\mathrm{PAR}$ & $\mathrm{TOL}+\mathrm{PAR}$ \\
\hline
\end{tabular}

$\mathrm{O}_{x}$ production from lumped-mechanism species are reassigned to the VOCs of Table 2 by scaling the $\mathrm{O}_{x}$ production of the mechanism species by the fractional contribution of each represented VOC. For example, TOL in RACM2 represents toluene and ethylbenzene with fractional contributions of 0.87 and 0.13 to TOL emissions. Scaling the $\mathrm{O}_{x}$ production from TOL by these factors gives the $\mathrm{O}_{x}$ production from toluene and ethylbenzene in RACM2.

Many reduced mechanisms use an operator species as a surrogate for $\mathrm{RO}_{2}$ during VOC degradation enabling these mechanisms to produce $\mathrm{O}_{x}$ while minimising the number of $\mathrm{RO}_{2}$ species represented. $\mathrm{O}_{x}$ production from operator species is assigned as $\mathrm{O}_{x}$ production from the organic degradation species producing the operator. This allocation technique is also used to assign $\mathrm{O}_{x}$ production from $\mathrm{HO}_{2}$ via Reaction (R7).

\subsubsection{Definition of TOPP}

Attributing $\mathrm{O}_{x}$ production to individual VOCs using the tagging approach is the basis for calculating the TOPP of a VOC, which is defined as the number of $\mathrm{O}_{x}$ molecules produced per emitted molecule of VOC. The TOPP value of a VOC that is not represented explicitly in a chemical mechanism is calculated by multiplying the TOPP value of the mechanism species representing the VOCs by the ratio of the carbon numbers of the VOCs to the mechanism species. For example, CB05 represents hexane as 6 PAR, so the TOPP value of hexane in the CB05 is 6 times the TOPP of PAR. MOZART-4 represents hexane with the five carbon species BIGALK. Thus, hexane emissions are represented molecule for molecule as $\frac{6}{5}$ of the equivalent number of molecules of BIGALK, and the TOPP value of hexane in MOZART-4 is calculated by multiplying the TOPP value of BIGALK by $\frac{6}{5}$.

\section{Results}

\subsection{Ozone time series and $O_{x}$ production budgets}

Figure 1 shows the time series of $\mathrm{O}_{3}$ mixing ratios obtained with each mechanism. There is an 8 ppbv difference in $\mathrm{O}_{3}$ mixing ratios on the first day between RADM2, which has the highest $\mathrm{O}_{3}$, and $\mathrm{RACM} 2$, which has the lowest $\mathrm{O}_{3}$ mixing ratios when not considering the outlier time series of RACM. The difference between RADM2 and RACM, the low outlier, was $21 \mathrm{ppbv}$ on the first day. The $\mathrm{O}_{3}$ mixing ratios in 


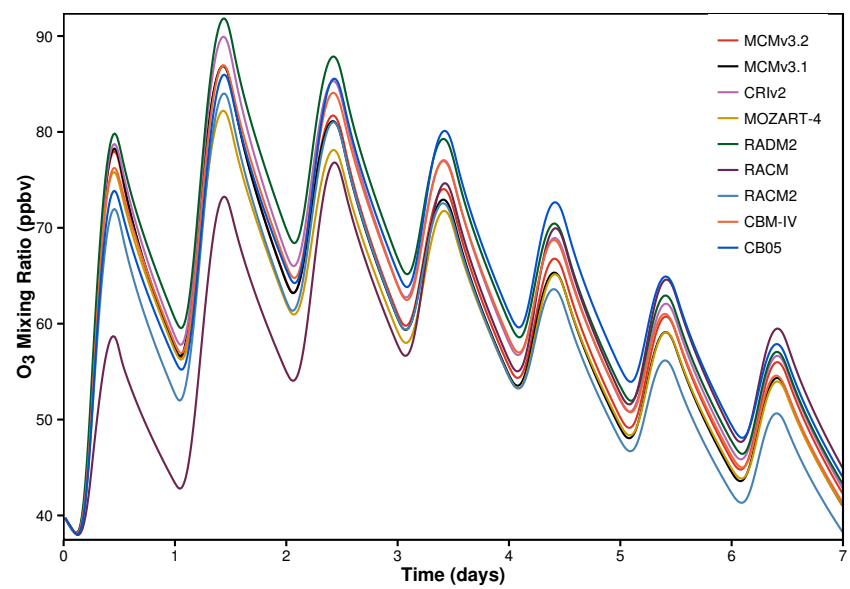

Figure 1. Time series of $\mathrm{O}_{3}$ mixing ratios obtained using each mechanism.

the CRI v2 are larger than those in the MCM v3.1, which is similar to the results in Jenkin et al. (2008) where the $\mathrm{O}_{3}$ mixing ratios of the CRI v2 and MCM v3.1 are compared over a 5 -day period.

The $\mathrm{O}_{3}$ mixing ratios in Fig. 1 are influenced by the approaches used in developing the chemical mechanisms and not a function of the explicitness of the chemical mechanism. For example, the $\mathrm{O}_{3}$ mixing ratios obtained using the Carbon Bond mechanisms (CBM-IV and CB05) compare well with the MCM despite both Carbon Bond mechanisms having $\sim 1 \%$ of the number of reactions in the MCM v3.2. Also, the $\mathrm{O}_{3}$ mixing ratios from RACM2 and RADM2 show similar absolute differences from that of the MCM despite RACM2 having more than double the number of reactions of RADM2.

The day-time $\mathrm{O}_{x}$ production budgets allocated to individual VOCs for each mechanism are shown in Fig. 2. The relationships between $\mathrm{O}_{3}$ mixing ratios in Fig. 1 are mirrored in Fig. 2 where mechanisms producing high amounts of $\mathrm{O}_{x}$ also have high $\mathrm{O}_{3}$ mixing ratios. The conditions in the box model lead to a daily maximum of $\mathrm{OH}$ that increases with each day leading to an increase on each day in both the reaction rate of the $\mathrm{OH}$ oxidation of $\mathrm{CH}_{4}$ and the daily contribution of $\mathrm{CH}_{4}$ to $\mathrm{O}_{x}$ production.

The first-day mixing ratios of $\mathrm{O}_{3}$ in RACM are lower than other mechanisms due to a lack of $\mathrm{O}_{x}$ production from aromatic VOCs on the first day in RACM (Fig. 2). Aromatic degradation chemistry in RACM results in net loss of $\mathrm{O}_{x}$ on the first day, described later in Sect. 3.2.1.

RADM2 is the only reduced mechanism that produces higher $\mathrm{O}_{3}$ mixing ratios than the more detailed mechanisms ( MCM v3.2, MCM v3.1 and CRI v2). Higher mixing ratios of $\mathrm{O}_{3}$ in RADM2 are produced due to increased $\mathrm{O}_{x}$ production from propane compared to the MCM v3.2; on the first day, the $\mathrm{O}_{x}$ production from propane in RADM2 is triple that of the MCM v3.2 (Fig. 2). Propane is represented as HC3 in

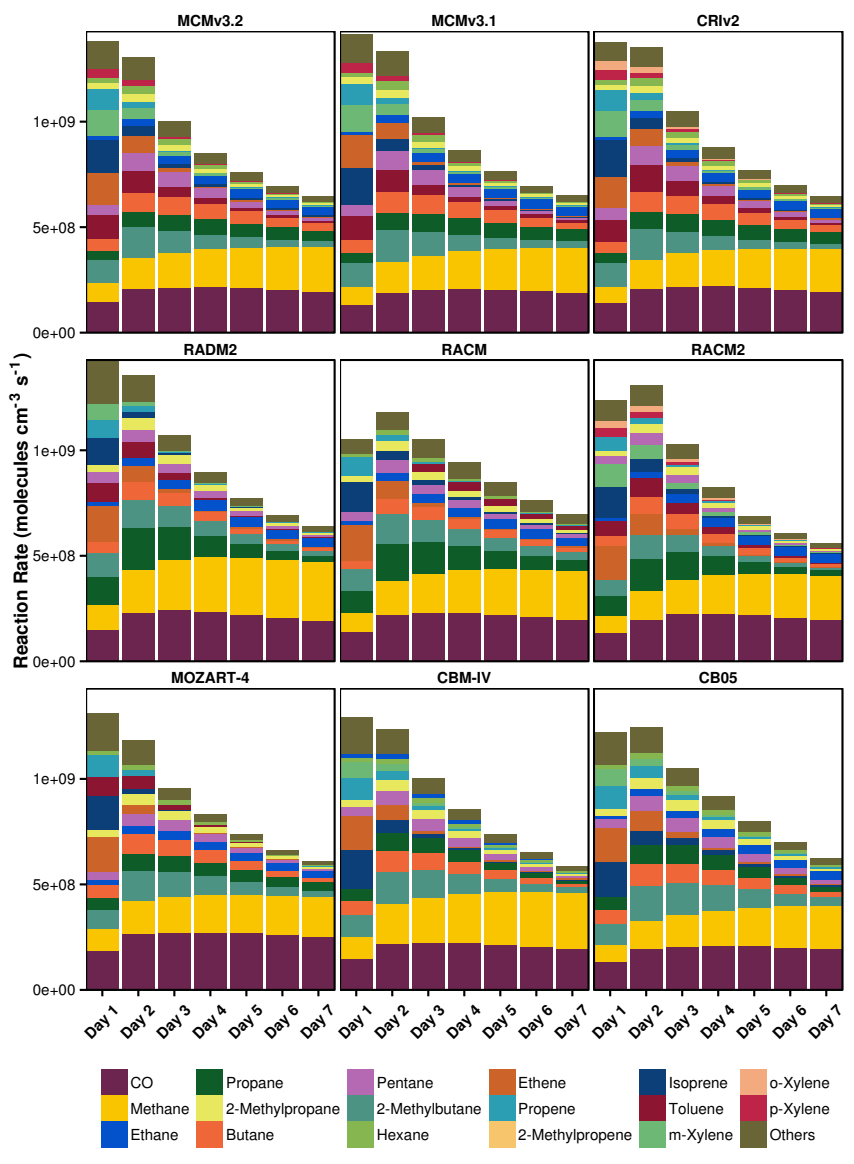

Figure 2. Day-time $\mathrm{O}_{x}$ production budgets in each mechanism allocated to individual VOCs.

RADM2 (Stockwell et al., 1990) and the degradation of HC3 has a lower yield of the less-reactive ketones compared to the MCM. The further degradation of ketones hinders $\mathrm{O}_{\mathrm{x}}$ production due to the low $\mathrm{OH}$ reactivity and photolysis rate of ketones. Secondary degradation of $\mathrm{HC} 3$ proceeds through the degradation of acetaldehyde $\left(\mathrm{CH}_{3} \mathrm{CHO}\right)$ propagating $\mathrm{O}_{\mathrm{x}}$ production through the reactions of $\mathrm{CH}_{3} \mathrm{CO}_{3}$ and $\mathrm{CH}_{3} \mathrm{O}_{2}$ with NO. Thus, the lower ketone yields lead to increased $\mathrm{O}_{x}$ production from propane degradation in RADM2 compared to the MCM v3.2.

\subsection{Time-dependent $O_{x}$ production}

Time series of daily TOPP values for each VOC are presented in Fig. 3 and the cumulative TOPP values at the end of the model run obtained for each VOC using each of the mechanisms, normalised by the number of atoms of $\mathrm{C}$ in each VOC are presented in Table 3. In the MCM and CRI v2, the cumulative TOPP values obtained for each VOC show that by the end of the model run, larger alkanes have produced more $\mathrm{O}_{x}$ per unit of reactive $\mathrm{C}$ than alkenes or aromatic VOCs. By the end of the runs using the lumped-structure mechanisms (CBM-IV and CB05), alkanes produce similar 


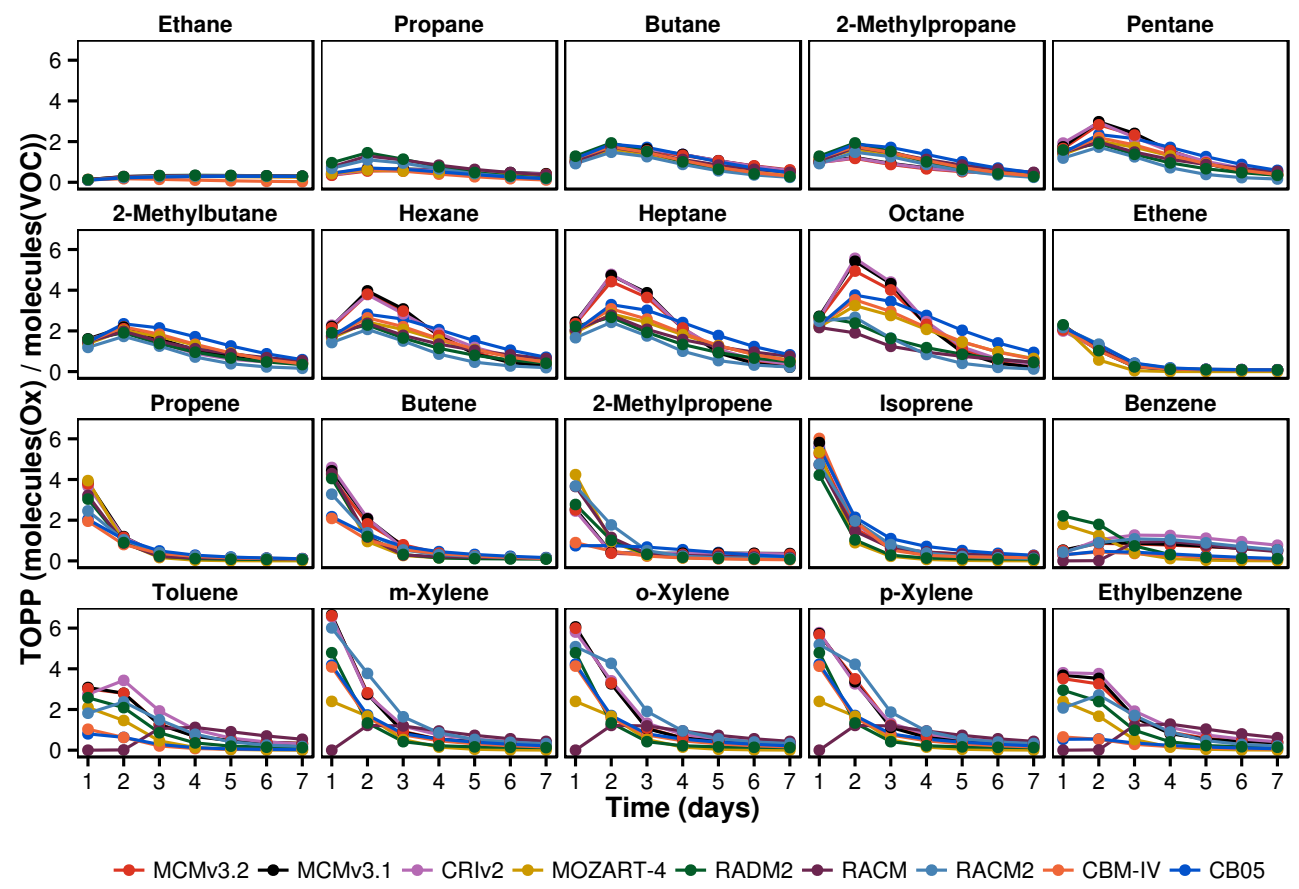

Figure 3. TOPP value time series using each mechanism for each VOC.

Table 3. Cumulative TOPP values at the end of the model run for all VOCs with each mechanism, normalised by the number of $\mathrm{C}$ atoms in each VOC.

\begin{tabular}{|c|c|c|c|c|c|c|c|c|c|}
\hline NMVOCs & MCM v3.2 & MCM v3.1 & CRI v2 & MOZART-4 & RADM2 & RACM & RACM2 & CBM-IV & CB05 \\
\hline \multicolumn{10}{|c|}{ Alkanes } \\
\hline Ethane & 0.9 & 1.0 & 0.9 & 0.9 & 1.0 & 1.0 & 0.9 & 0.3 & 0.9 \\
\hline Propane & 1.1 & 1.2 & 1.2 & 1.1 & 1.8 & 1.8 & 1.4 & 0.9 & 1.0 \\
\hline Butane & 2.0 & 2.0 & 2.0 & 1.7 & 1.8 & 1.8 & 1.4 & 1.7 & 2.1 \\
\hline 2-Methylpropane & 1.3 & 1.3 & 1.3 & 1.7 & 1.8 & 1.8 & 1.4 & 1.7 & 2.1 \\
\hline Pentane & 2.1 & 2.1 & 2.2 & 1.7 & 1.5 & 1.6 & 1.1 & 1.7 & 2.1 \\
\hline 2-Methylbutane & 1.6 & 1.6 & 1.5 & 1.7 & 1.5 & 1.6 & 1.1 & 1.7 & 2.1 \\
\hline Hexane & 2.1 & 2.1 & 2.2 & 1.7 & 1.5 & 1.6 & 1.1 & 1.7 & 2.1 \\
\hline Heptane & 2.0 & 2.1 & 2.2 & 1.7 & 1.5 & 1.6 & 1.1 & 1.7 & 2.1 \\
\hline Octane & 2.0 & 2.0 & 2.2 & 1.7 & 1.2 & 1.0 & 1.0 & 1.7 & 2.1 \\
\hline \multicolumn{10}{|c|}{ Alkenes } \\
\hline Ethene & 1.9 & 1.9 & 1.9 & 1.4 & 2.0 & 2.0 & 2.2 & 1.9 & 2.2 \\
\hline Propene & 1.9 & 2.0 & 1.9 & 1.7 & 1.5 & 1.6 & 1.5 & 1.2 & 1.4 \\
\hline Butene & 1.9 & 2.0 & 2.0 & 1.5 & 1.5 & 1.6 & 1.5 & 0.8 & 0.9 \\
\hline 2-Methylpropene & 1.1 & 1.2 & 1.2 & 1.5 & 1.1 & 1.5 & 1.6 & 0.5 & 0.5 \\
\hline Isoprene & 1.8 & 1.8 & 1.8 & 1.3 & 1.2 & 1.6 & 1.7 & 1.9 & 2.1 \\
\hline \multicolumn{10}{|c|}{ Aromatics } \\
\hline Benzene & 0.8 & 0.8 & 1.1 & 0.6 & 0.9 & 0.6 & 0.9 & 0.3 & 0.3 \\
\hline Toluene & 1.3 & 1.3 & 1.5 & 0.6 & 0.9 & 0.6 & 1.0 & 0.3 & 0.3 \\
\hline m-Xylene & 1.5 & 1.5 & 1.6 & 0.6 & 0.9 & 0.6 & 1.7 & 0.9 & 1.0 \\
\hline p-Xylene & 1.5 & 1.5 & 1.6 & 0.6 & 0.9 & 0.6 & 1.7 & 0.9 & 1.0 \\
\hline o-Xylene & 1.5 & 1.5 & 1.6 & 0.6 & 0.9 & 0.6 & 1.7 & 0.9 & 1.0 \\
\hline Ethylbenzene & 1.3 & 1.4 & 1.5 & 0.6 & 0.9 & 0.6 & 1.0 & 0.2 & 0.3 \\
\hline
\end{tabular}


amounts of $\mathrm{O}_{x}$ per reactive $\mathrm{C}$, while aromatic VOCs and some alkenes produce less $\mathrm{O}_{x}$ per reactive $\mathrm{C}$ than the MCM. However, in lumped-molecule mechanisms (MOZART-4, RADM2, RACM, RACM2), practically all VOCs produce less $\mathrm{O}_{x}$ per reactive $\mathrm{C}$ than the MCM by the end of the run. This lower efficiency of $\mathrm{O}_{x}$ production from many individual VOCs in lumped-molecule and lumped-structure mechanisms would lead to an underestimation of $\mathrm{O}_{3}$ levels downwind of an emission source, and a smaller contribution to background $\mathrm{O}_{3}$ when using lumped-molecule and lumpedstructure mechanisms.

The lumped-intermediate mechanism (CRI v2) produces the most similar $\mathrm{O}_{x}$ to the MCM v3.2 for each VOC, seen in Fig. 3 and Table 3. Higher variability in the time-dependent $\mathrm{O}_{x}$ production is evident for VOCs represented by lumpedmechanism species. For example, 2-methylpropene, represented in the reduced mechanisms by a variety of lumped species, has a higher spread in time-dependent $\mathrm{O}_{x}$ production than ethene, which is explicitly represented in each mechanism.

In general, the largest differences in $\mathrm{O}_{x}$ produced by aromatic and alkene species are on the first day of the simulations, while the largest inter-mechanism differences in $\mathrm{O}_{x}$ produced by alkanes are on the second and third days of the simulations. The reasons for these differences in behaviour will be explored in Sect. 3.2.1, which examines differences in first day $\mathrm{O}_{x}$ production between the chemical mechanisms, and Sect. 3.2.2, which examines the differences in $\mathrm{O}_{x}$ production on subsequent days.

\subsubsection{First-day ozone production}

The first-day TOPP values of each VOC from each mechanism, representing $\mathrm{O}_{3}$ production from freshly emitted VOCs near their source region, are compared to those obtained with the MCM v3.2 in Fig. 4. The root mean square error (RMSE) of all first-day TOPP values in each mechanism relative to those in the MCM v3.2 are also included in Fig. 4. The RMSE value of the CRI v2 shows that first-day $\mathrm{O}_{x}$ production from practically all the individual VOC matches that in the MCM v3.2. All other reduced mechanisms have much larger RMSE values indicating that the first-day $\mathrm{O}_{x}$ production from the majority of the VOCs differs from that in the MCM v3.2.

The reduced complexity of reduced mechanisms means that aromatic VOCs are typically represented by one or two mechanism species leading to differences in $\mathrm{O}_{x}$ production of the actual VOCs compared to the MCM v3.2. For example, all aromatic VOCs in MOZART-4 are represented as toluene, thus less-reactive aromatic VOCs, such as benzene, produce higher $\mathrm{O}_{x}$ whilst more-reactive aromatic VOCs, such as the xylenes, produce less $\mathrm{O}_{x}$ in MOZART-4 than the MCM v3.2. RACM2 includes explicit species representing benzene, toluene and each xylene resulting in $\mathrm{O}_{x}$ production

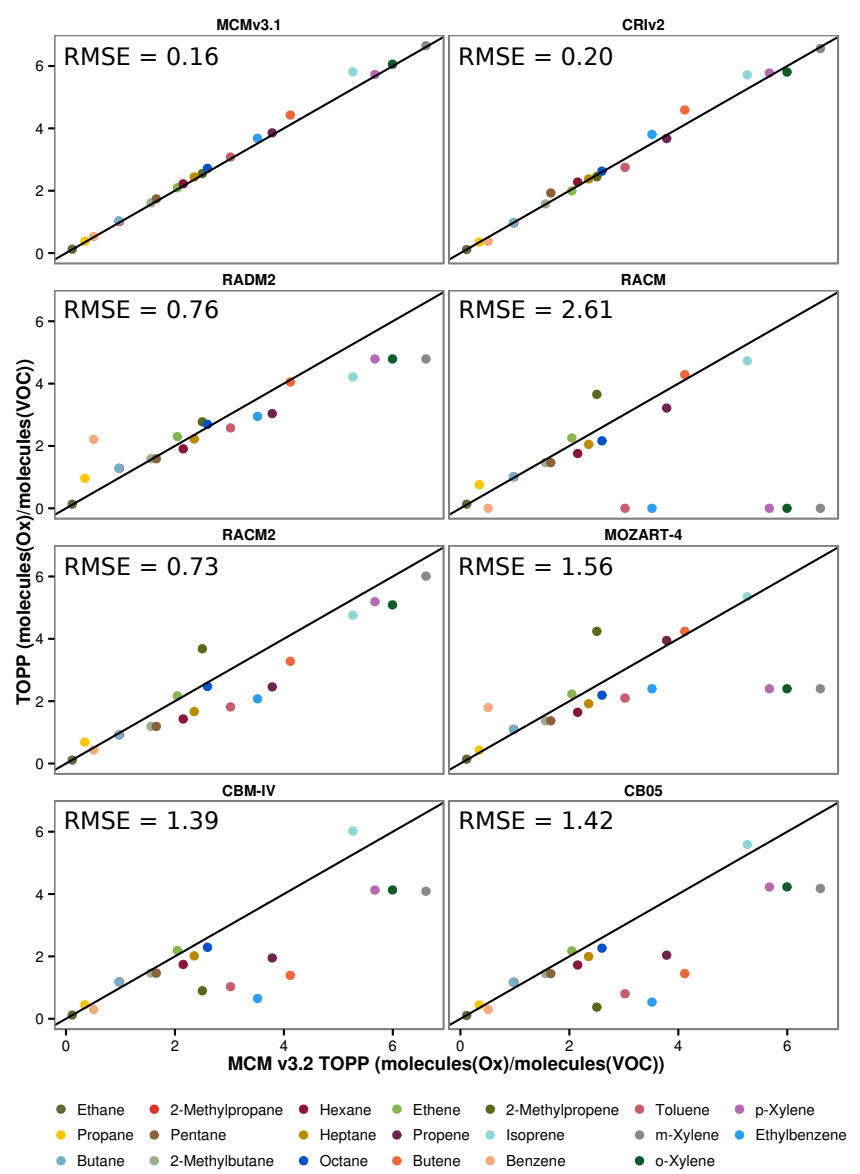

Figure 4. The first-day TOPP values for each VOC calculated using MCM v3.2 and the corresponding values in each mechanism. The root mean square error (RMSE) of each set of TOPP values is also displayed. The black line is the $1: 1$ line.

that is the most similar to the MCM v3.2 than other reduced mechanisms.

Figure 3 shows a high spread in $\mathrm{O}_{x}$ production from aromatic VOCs on the first day indicating that aromatic degradation is treated differently between mechanisms. Toluene degradation is examined in more detail by comparing the reactions contributing to $\mathrm{O}_{x}$ production and loss in each mechanism, shown in Fig. 5. These reactions are determined by following the "toluene" tags in the tagged version of each mechanism.

Toluene degradation in RACM includes several reactions consuming $\mathrm{O}_{x}$ that are not present in the MCM, resulting in net loss of $\mathrm{O}_{x}$ on the first 2 days. Ozonolysis of the cresol $\mathrm{OH}$ adduct mechanism species, ADDC, contributes significantly to $\mathrm{O}_{x}$ loss in RACM. This reaction was included in RACM due to improved cresol product yields when comparing RACM predictions with experimental data (Stockwell et al., 1997). Other mechanisms that include cresol OH adduct species do not include ozonolysis and these reactions are not included in the updated RACM2. 

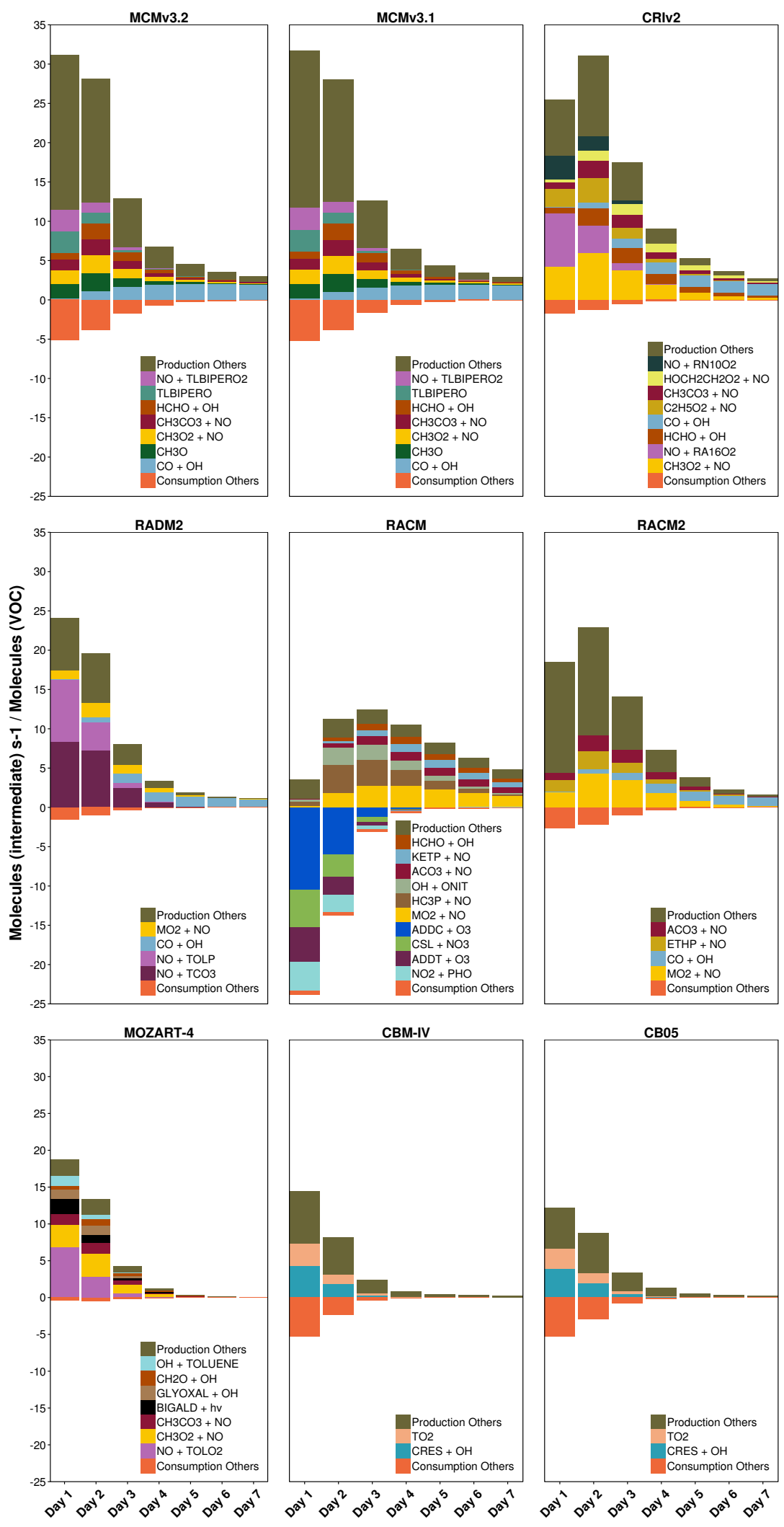

Figure 5. Day-time $\mathrm{O}_{x}$ production and loss budgets allocated to the responsible reactions during toluene degradation in all mechanisms. These reactions are presented using the species defined in each mechanism in Table 1. 
The total $\mathrm{O}_{x}$ produced on the first day during toluene degradation in each reduced mechanism is less than that in the MCM v3.2 (Fig. 5). Less $\mathrm{O}_{x}$ is produced in all reduced mechanisms due to a faster breakdown of the VOCs into smaller fragments than the MCM, described later in Sect. 3.3. Moreover, in CBM-IV and CB05, less $\mathrm{O}_{x}$ is produced during toluene degradation as reactions of the toluene degradation products $\mathrm{CH}_{3} \mathrm{O}_{2}$ and $\mathrm{CO}$ do not contribute to the $\mathrm{O}_{x}$ production budgets, which is not the case in any other mechanism (Fig. 5).

Maximum $\mathrm{O}_{x}$ production from toluene degradation in CRI v2 and RACM2 is reached on the second day in contrast to the MCM v3.2 which produces peak $\mathrm{O}_{x}$ on the first day. The second-day maximum of $\mathrm{O}_{x}$ production in CRI v2 and RACM2 from toluene degradation results from more efficient production of unsaturated dicarbonyls than the MCM v3.2. The degradation of unsaturated dicarbonyls produces peroxy radicals such as $\mathrm{C}_{2} \mathrm{H}_{5} \mathrm{O}_{2}$ which promote $\mathrm{O}_{x}$ production via reactions with $\mathrm{NO}$.

Unsaturated aliphatic VOCs generally produce similar amounts of $\mathrm{O}_{x}$ between mechanisms, especially explicitly represented VOCs, such as ethene and isoprene. On the other hand, unsaturated aliphatic VOCs that are not explicitly represented produce differing amounts of $\mathrm{O}_{x}$ between mechanisms (Fig. 3). For example, the $\mathrm{O}_{x}$ produced during 2methylpropene degradation varies between mechanisms; differing rate constants of initial oxidation reactions and nonrealistic secondary chemistry lead to these differences; further details are found in the Supplement.

Non-explicit representations of aromatic and unsaturated aliphatic VOCs coupled with differing degradation chemistry and a faster breakdown into smaller-size degradation products results in different $\mathrm{O}_{x}$ production in lumpedmolecule and lumped-structure mechanisms compared to the MCM v3.2.

\subsubsection{Ozone production on subsequent days}

Alkane degradation in CRI v2 and both MCMs produces a second-day maximum in $\mathrm{O}_{x}$ that increases with alkane carbon number (Fig. 3). The increase in $\mathrm{O}_{x}$ production on the second day is reproduced for each alkane by the reduced mechanisms, except octane in RADM2, RACM and RACM2. However, larger alkanes produce less $\mathrm{O}_{x}$ than the $\mathrm{MCM}$ on the second day in all lumped-molecule and lumpedstructure mechanisms.

The lumped-molecule mechanisms (MOZART-4, RADM2, RACM and RACM2) represent many alkanes by mechanism species which may lead to unrepresentative secondary chemistry for alkane degradation. For example, 3 times more $\mathrm{O}_{x}$ is produced during the degradation of propane in RADM2 than the MCM v3.2 on the first day (Fig. 2). Propane is represented in RADM2 by the mechanism species HC3 which also represents other classes of VOCs, such as alcohols. The secondary chemistry of $\mathrm{HC} 3$ is

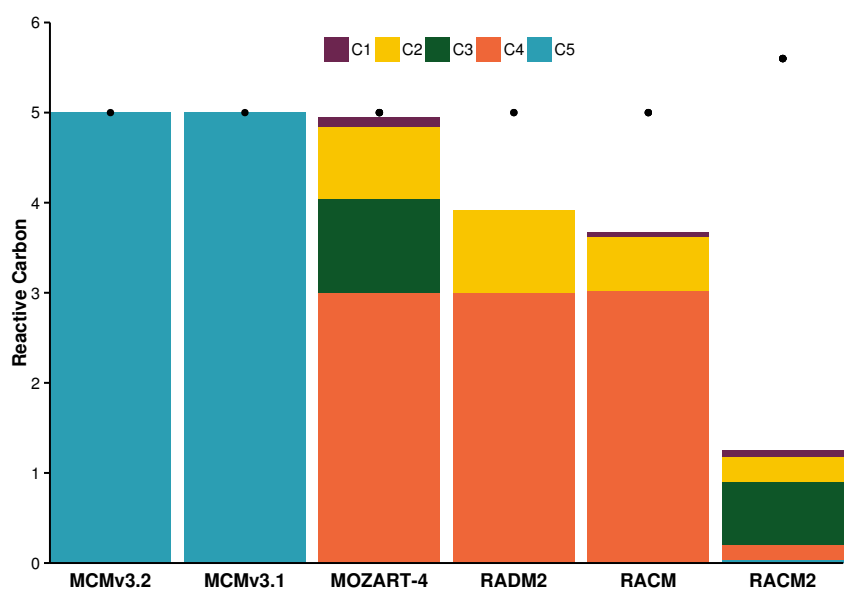

Figure 6. The distribution of reactive carbon in the products of the reaction between NO and the pentyl peroxy radical in lumpedmolecule mechanisms compared to the MCM. The black dot represents the reactive carbon of the pentyl peroxy radical.

tailored to produce $\mathrm{O}_{x}$ from these different VOCs and differs from alkane degradation in the MCM $\mathrm{v} 3.2$ by producing less ketones in RADM2.

As will be shown in Sect. 3.3, another feature of reduced mechanisms is that the breakdown of emitted VOCs into smaller-sized degradation products is faster than the MCM. Alkanes are broken down quicker in CBM-IV, CB05, RADM2, RACM and RACM2 through a higher rate of reactive carbon loss than the MCM v3.2 (shown for pentane and octane in Fig. 8); reactive carbon is lost through reactions not conserving carbon. Despite many degradation reactions of alkanes in MOZART-4 almost conserving carbon, the organic products have less reactive carbon than the organic reactant also speeding up the breakdown of the alkane compared to the MCM v3.2.

For example, Fig. 6 shows the distribution of reactive carbon in the reactants and products from the reaction of NO with the pentyl peroxy radical in both MCMs and each lumped-molecule mechanism. In all the lumped-molecule mechanisms, the individual organic products have less reactive carbon than the organic reactant. Moreover, in RADM2, RACM and RACM2, this reaction does not conserve reactive carbon leading to faster loss rates of reactive carbon.

The faster breakdown of alkanes in lumped-molecule and lumped-structure mechanisms on the first day limits the amount of $\mathrm{O}_{x}$ produced on the second day, as less of the larger-sized degradation products are available for further degradation and $\mathrm{O}_{x}$ production.

\subsection{Treatment of degradation products}

The time-dependent $\mathrm{O}_{x}$ production of the different VOCs in Fig. 3 results from the varying rates at which VOCs break up into smaller fragments (Butler et al., 2011). Varying breakdown rates of the same VOCs between mechanisms could 


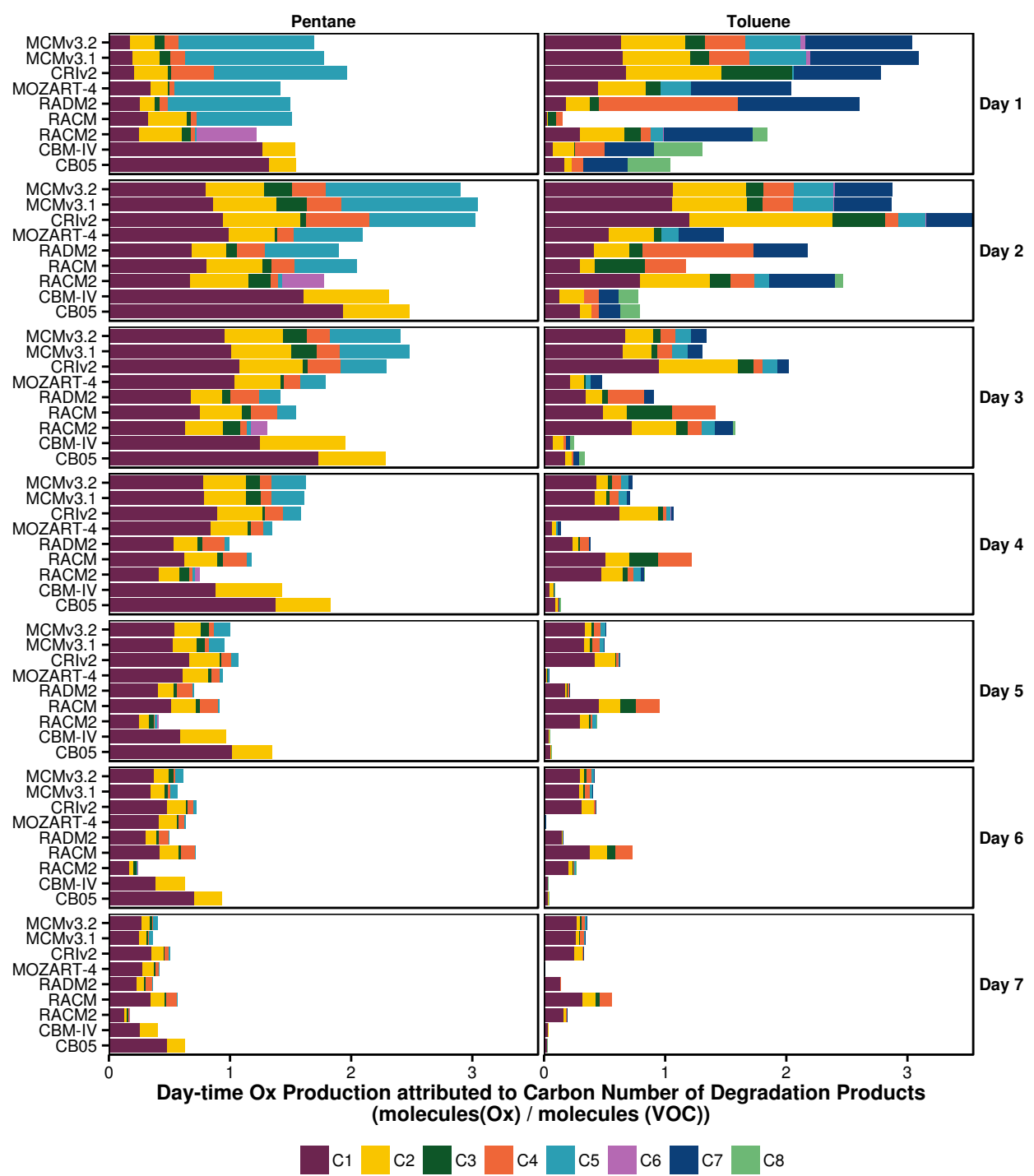

Figure 7. Day-time $\mathrm{O}_{x}$ production during pentane and toluene degradation is attributed to the number of carbon atoms of the degradation products for each mechanism.

explain the different time-dependent $\mathrm{O}_{x}$ production between mechanisms. The breakdown of pentane and toluene between mechanisms is compared in Fig. 7 by allocating the $\mathrm{O}_{x}$ production to the number of carbon atoms in the degradation products responsible for $\mathrm{O}_{x}$ production on each day of the model run in each mechanism. Some mechanism species in RADM2, RACM and RACM2 have fractional carbon numbers (Stockwell et al., 1990, 1997; Goliff et al., 2013) and $\mathrm{O}_{x}$ production from these species was reassigned as $\mathrm{O}_{x}$ production of the nearest integral carbon number.

The degradation of pentane, a five-carbon VOC, on the first day in the MCM v3.2 produces up to $50 \%$ more $\mathrm{O}_{x}$ from degradation products also having five carbon atoms than any reduced mechanism. Moreover, the contribution of the degradation products having five carbon atoms in the MCM v3.2 is consistently higher throughout the model run than in re- duced mechanisms (Fig. 7). Despite producing less total $\mathrm{O}_{x}$, reduced mechanisms produce up to double the amount of $\mathrm{O}_{x}$ from degradation products with one carbon atom than in the MCM v3.2. The lower contribution of larger degradation products indicates that pentane is generally broken down faster in reduced mechanisms, consistent with the specific example shown for the breakdown of the pentyl peroxy radical in Fig. 6.

The rate of change in reactive carbon during pentane, octane and toluene degradation was determined by multiplying the rate of each reaction occurring during pentane, octane and toluene degradation by its net change in carbon, shown in Fig. 8. Pentane is broken down faster in CBM-IV, CB05, RADM2, RACM and RACM2 by losing reactive carbon more quickly than the MCM v3.2. MOZART-4 also breaks pentane down into smaller-sized products quicker 


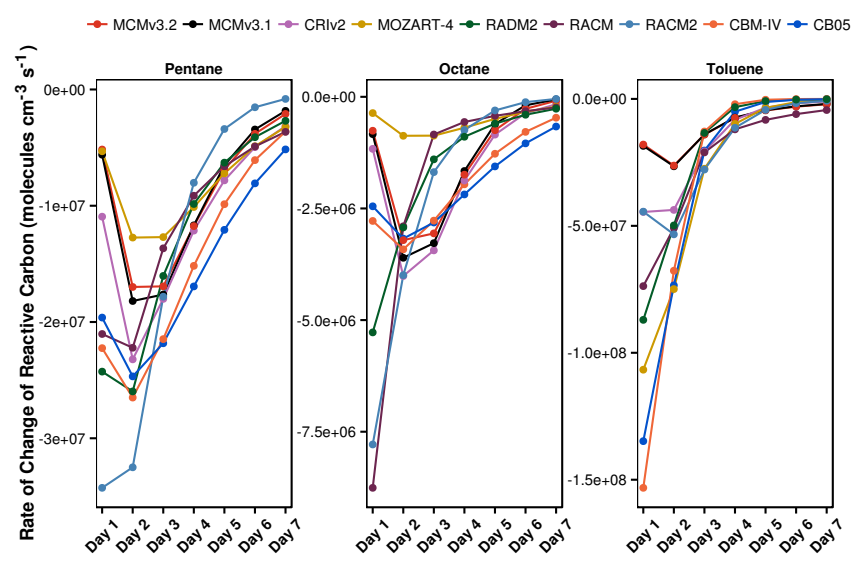

Figure 8. Daily rate of change in reactive carbon during pentane, octane and toluene degradation. Octane is represented by the five carbon species, BIGALK, in MOZART-4.

than the MCM v3.2 as reactions during pentane degradation in MOZART-4 have organic products whose carbon number is less than the organic reactant, described in Sect. 3.2.2. The faster breakdown of pentane on the first day limits the amount of reactive carbon available to produce further $\mathrm{O}_{x}$ on subsequent days leading to lower $\mathrm{O}_{x}$ production after the first day in reduced mechanisms.

Figure 3 showed that octane degradation produces peak $\mathrm{O}_{x}$ on the first day in RADM2, RACM and RACM2 in contrast to all other mechanisms where peak $\mathrm{O}_{x}$ is produced on the second day. Octane degradation in RADM2, RACM and RACM2 loses reactive carbon much faster than any other mechanism on the first day so that there are not enough degradation products available to produce peak $\mathrm{O}_{x}$ on the second day (Fig. 8). This loss of reactive carbon during alkane degradation leads to the lower accumulated ozone production from these VOCs shown in Table 3.

As seen in Fig. 3, $\mathrm{O}_{x}$ produced during toluene degradation has a high spread between the mechanisms. Figure 7 shows differing distributions of the sizes of the degradation products that produce $\mathrm{O}_{x}$. All reduced mechanisms omit $\mathrm{O}_{x}$ production from at least one degradation fragment size which produces $\mathrm{O}_{x}$ in the MCM v3.2, indicating that toluene is also broken down more quickly in the reduced mechanisms than the more explicit mechanisms. For example, toluene degradation in RACM2 does not produce $\mathrm{O}_{x}$ from degradation products with six carbons, as is the case in the MCM v3.2. Figure 8 shows that all reduced mechanisms lose reactive carbon during toluene degradation faster than the MCM v3.2. Thus, the degradation of aromatic VOCs in reduced mechanisms are unable to produce similar amounts of $\mathrm{O}_{x}$ as the explicit mechanisms.

\section{Conclusions}

Tagged ozone production potentials (TOPPs) were used to compare $\mathrm{O}_{x}$ production during VOC degradation in reduced chemical mechanisms to the near-explicit MCM v3.2. Firstday mixing ratios of $\mathrm{O}_{3}$ are similar to the MCM v3.2 for most mechanisms; the $\mathrm{O}_{3}$ mixing ratios in RACM were much lower than the MCM v3.2 due to a lack of $\mathrm{O}_{x}$ production from the degradation of aromatic VOCs. Thus, RACM may not be the appropriate chemical mechanism when simulating atmospheric conditions having a large fraction of aromatic VOCs.

The lumped-intermediate mechanism, CRI v2, produces the most similar amounts of $\mathrm{O}_{x}$ to the MCM v3.2 for each VOC. The largest differences between $\mathrm{O}_{x}$ production in CRI v2 and MCM v3.2 were obtained for aromatic VOCs; however, overall these differences were much lower than any other reduced mechanism. Thus, when developing chemical mechanisms, the technique of using lumped-intermediate species whose degradation are based upon more detailed mechanism should be considered.

Many VOCs are broken down into smaller-sized degradation products faster on the first day in reduced mechanisms than the MCM v3.2 leading to lower amounts of largersized degradation products that can further degrade and produce $\mathrm{O}_{x}$. Thus, many VOCs in reduced mechanisms produce a lower maximum of $\mathrm{O}_{x}$ and lower total $\mathrm{O}_{x}$ per reactive $\mathrm{C}$ by the end of the run than the MCM v3.2. This lower $\mathrm{O}_{x}$ production from many VOCs in reduced mechanisms leads to lower $\mathrm{O}_{3}$ mixing ratios compared to the MCM v3.2.

Alkanes produce maximum $\mathrm{O}_{3}$ on the second day of simulations and this maximum is lower in reduced mechanisms than the MCM v3.2 due to the faster breakdown of alkanes into smaller-sized degradation products on the first day. The lower maximum in $\mathrm{O}_{3}$ production during alkane degradation in reduced mechanisms leads to an underestimation of the $\mathrm{O}_{3}$ levels downwind of VOC emissions and an underestimation of the VOC contribution to tropospheric background $\mathrm{O}_{3}$ when using reduced mechanisms in regional or global modelling studies.

This study has determined the maximum potential of VOCs represented in reduced mechanisms to produce $\mathrm{O}_{3}$; this potential may not be reached as ambient $\mathrm{NO}_{x}$ conditions may not induce $\mathrm{NO}_{x}-\mathrm{VOC}$-sensitive chemistry. Moreover, the maximum potential of VOCs to produce $\mathrm{O}_{3}$ may not be reached when using these reduced mechanisms in 3-D models due to the influence of additional processes, such as mixing and meteorology. Future work shall examine the extent to which the maximum potential of VOCs to produce $\mathrm{O}_{3}$ in reduced chemical mechanisms is reached using ambient $\mathrm{NO}_{x}$ conditions and including processes found in 3-D models.

The Supplement related to this article is available online at doi:10.5194/acp-15-8795-2015-supplement. 
Acknowledgements. The authors would like to thank Mike Jenkin and William Stockwell for their helpful reviews, as well as Mark Lawrence and Peter J. H. Builtjes for valuable discussions during the preparation of this manuscript.

Edited by: R. Harley

\section{References}

Ahmadov, R., McKeen, S., Trainer, M., Banta, R., Brewer, A., Brown, S., Edwards, P. M., de Gouw, J. A., Frost, G. J., Gilman, J., Helmig, D., Johnson, B., Karion, A., Koss, A., Langford, A., Lerner, B., Olson, J., Oltmans, S., Peischl, J., Pétron, G., Pichugina, Y., Roberts, J. M., Ryerson, T., Schnell, R., Senff, C., Sweeney, C., Thompson, C., Veres, P. R., Warneke, C., Wild, R., Williams, E. J., Yuan, B., and Zamora, R.: Understanding high wintertime ozone pollution events in an oil- and natural gasproducing region of the western US, Atmos. Chem. Phys., 15, 411-429, doi:10.5194/acp-15-411-2015, 2015.

Atkinson, R.: Atmospheric chemistry of VOCs and $\mathrm{NO}_{x}$, Atmos. Environ., 34, 2063-2101, 2000.

Baker, A. K., Beyersdorf, A. J., Doezema, L. A., Katzenstein, A., Meinardi, S., Simpson, I. J., Blake, D. R., and Rowland, F. S.: Measurements of nonmethane hydrocarbons in 28 United States cities, Atmos. Environ., 42, 170-182, 2008.

Baklanov, A., Schlünzen, K., Suppan, P., Baldasano, J., Brunner, D., Aksoyoglu, S., Carmichael, G., Douros, J., Flemming, J., Forkel, R., Galmarini, S., Gauss, M., Grell, G., Hirtl, M., Joffre, S., Jorba, O., Kaas, E., Kaasik, M., Kallos, G., Kong, X., Korsholm, U., Kurganskiy, A., Kushta, J., Lohmann, U., Mahura, A., Manders-Groot, A., Maurizi, A., Moussiopoulos, N., Rao, S. T., Savage, N., Seigneur, C., Sokhi, R. S., Solazzo, E., Solomos, S., Sørensen, B., Tsegas, G., Vignati, E., Vogel, B., and Zhang, Y.: Online coupled regional meteorology chemistry models in Europe: current status and prospects, Atmos. Chem. Phys., 14, 317-398, doi:10.5194/acp-14-317-2014, 2014.

Bloss, C., Wagner, V., Jenkin, M. E., Volkamer, R., Bloss, W. J., Lee, J. D., Heard, D. E., Wirtz, K., Martin-Reviejo, M., Rea, G., Wenger, J. C., and Pilling, M. J.: Development of a detailed chemical mechanism (MCMv3.1) for the atmospheric oxidation of aromatic hydrocarbons, Atmos. Chem. Phys., 5, 641-664, doi:10.5194/acp-5-641-2005, 2005.

Butler, T. M., Lawrence, M. G., Taraborrelli, D., and Lelieveld, J.: Multi-day ozone production potential of volatile organic compounds calculated with a tagging approach, Atmos. Environ., 45, 4082-4090, 2011.

Carter, W. P. L.: Development of ozone reactivity scales for volatile organic compounds, J. Air Waste Manage., 44, 881-899, 1994.

Damian, V., Sandu, A., Damian, M., Potra, F., and Carmichael, G.: The kinetic preprocessor KPP - a software environment for solving chemical kinetics, Comput. Chem. Eng., 26, 1567-1579, 2002.

Derwent, R. G., Jenkin, M. E., and Saunders, S. M.: Photochemical ozone creation potentials for a large number of reactive hydrocarbons under European conditions, Atmos. Environ., 30, 181-199, 1996.

Derwent, R. G., Jenkin, M. E., Saunders, S. M., and Pilling, M. J.: Photochemical ozone creation potentials for organic compounds in Northwest Europe calculated with a master chemical mechanism, Atmos. Environ., 32, 2429-2441, 1998.

Derwent, R. G., Jenkin, M. E., Pilling, M. J., Carter, W. P. L., and Kaduwela, A.: Reactivity scales as comparative tools for chemical mechanisms, J. Air Waste Manage., 60, 914-924, 2010.

Derwent, R. G., Utember, S. R., Jenkin, M. E., and Shallcross, D. E.: Tropospheric ozone production regions and the intercontinental origins of surface ozone over Europe, Atmos. Environ., 112, 216-224, 2015

Dodge, M.: Chemical oxidant mechanisms for air quality modeling: critical review, Atmos. Environ., 34, 2103-2130, 2000.

Dunker, A. M., Kumar, S., and Berzins, P. H.: A comparison of chemical mechanisms used in atmospheric models, Atmos. Environ., 18, 311-321, 1984.

Dunker, A. M., Koo, B,, and Yarwood, G.: Source Apportionment of the Anthropogenic Increment to Ozone, Formaldehyde, and Nitrogen Dioxide by the Path- Integral Method in a 3D Model, Environ. Sci. Technol., 49, 6751-6759, 2015.

EEA: Air quality in Europe - 2014 report, Tech. Rep. 5/2014, European Environmental Agency, Publications Office of the European Union, doi:10.2800/22847, 2014.

Emmerson, K. M. and Evans, M. J.: Comparison of tropospheric gas-phase chemistry schemes for use within global models, Atmos. Chem. Phys., 9, 1831-1845, doi:10.5194/acp-9-1831-2009, 2009.

Emmons, L. K., Walters, S., Hess, P. G., Lamarque, J.-F., Pfister, G. G., Fillmore, D., Granier, C., Guenther, A., Kinnison, D., Laepple, T., Orlando, J., Tie, X., Tyndall, G., Wiedinmyer, C., Baughcum, S. L., and Kloster, S.: Description and evaluation of the Model for Ozone and Related chemical Tracers, version 4 (MOZART-4), Geosci. Model Dev., 3, 43-67, doi:10.5194/gmd3-43-2010, 2010.

Foster, P. N., Prentice, I. C., Morfopoulos, C., Siddall, M., and van Weele, M.: Isoprene emissions track the seasonal cycle of canopy temperature, not primary production: evidence from remote sensing, Biogeosciences, 11, 3437-3451, doi:10.5194/bg-11-34372014, 2014.

Gery, M. W., Whitten, G. Z., Killus, J. P., and Dodge, M. C.: A photochemical kinetics mechanism for urban and regional scale computer modeling, J. Geophys. Res., 94, 12925-12956, 1989.

Goliff, W. S., Stockwell, W. R., and Lawson, C. V.: The regional atmospheric chemistry mechanism, version 2, Atmos. Environ., 68, 174-185, 2013.

Goliff, W. S., Luria, M., Blake, D. R., Zielinska, B., Hallar, G., Valente, R. J., Lawson, C. V., and Stockwell, W. R.: Nighttime air quality under desert conditions, Atmos. Environ., 114, 102-111, 2015.

Harwood, M., Roberts, J., Frost, G., Ravishankara, A., and Burkholder, J.: Photochemical studies of $\mathrm{CH}_{3} \mathrm{C}(\mathrm{O}) \mathrm{OONO}_{2}$ (PAN) and $\mathrm{CH}_{3} \mathrm{CH}_{2} \mathrm{C}(\mathrm{O}) \mathrm{OONO}_{2}(\mathrm{PPN}): \mathrm{NO}_{3}$ quantum yields, J. Phys. Chem. A, 107, 1148-1154, 2003.

Hogo, H. and Gery, M.: User's guide for executing OZIPM-4 (Ozone Isopleth Plotting with Optional Mechanisms, Version 4) with CBM-IV (Carbon-Bond Mechanisms-IV) or optional mechanisms. Volume 1. Description of the ozone isopleth plotting package. Version 4, Tech. rep., US Environmental Protection Agency, Durham, North Carolina, USA, 1989.

Hou, X., Zhu, B., Fei, D., and Wang, D.: The impacts of summer monsoons on the ozone budget of the atmospheric boundary 
layer of the Asia-Pacific region, Sci. Total Environ., 502, 641$649,2015$.

HTAP: Hemispheric Transport of Air Pollution 2010, Part A: Ozone and Particulate Matter, Air Pollution Studies No.17, Geneva, Switzerland, 2010.

Jenkin, M. E. and Clemitshaw, K. C.: Ozone and other secondary photochemical pollutants: chemical processes governing their formation in the planetary boundary layer, Atmos. Environ., 34, 2499-2527, 2000.

Jenkin, M. E., Saunders, S. M., and Pilling, M. J.: The tropospheric degradation of volatile organic compounds: a protocol for mechanism development, Atmos. Environ., 31, 81-104, 1997.

Jenkin, M. E., Saunders, S. M., Wagner, V., and Pilling, M. J.: Protocol for the development of the Master Chemical Mechanism, MCM v3 (Part B): tropospheric degradation of aromatic volatile organic compounds, Atmos. Chem. Phys., 3, 181-193, doi:10.5194/acp-3-181-2003, 2003.

Jenkin, M. E., Watson, L. A., Utembe, S. R., and Shallcross, D. E.: A Common Representative Intermediates (CRI) mechanism for VOC degradation. Part 1: Gas phase mechanism development, Atmos. Environ., 42, 7185-7195, 2008.

Kleinman, L. I.: Seasonal dependence of boundary layer peroxide concentration: the low and high $\mathrm{NO}_{x}$ regimes, J. Geophys. Res., 96, 20721-20733, 1991

Kleinman, L. I.: Low and high $\mathrm{NO}_{x}$ tropospheric photochemistry, J. Geophys. Res., 99, 16831-16838, 1994.

Koss, A. R., de Gouw, J., Warneke, C., Gilman, J. B., Lerner, B. M., Graus, M., Yuan, B., Edwards, P., Brown, S. S., Wild, R., Roberts, J. M., Bates, T. S., and Quinn, P. K.: Photochemical aging of volatile organic compounds associated with oil and natural gas extraction in the Uintah Basin, UT, during a wintertime ozone formation event, Atmos. Chem. Phys., 15, 5727-5741, doi:10.5194/acp-15-5727-2015, 2015.

Kuhn, M., Builtjes, P. J. H., Poppe, D., Simpson, D., Stockwell, W. R., Andersson-Sköld, Y., Baart, A., Das, M., Fiedler, F., Hov, Ø., Kirchner, F., Makar, P. A., Milford, J. B., Roemer, M. G. M., Ruhnke, R., Strand, A., Vogel, B., and Vogel, H.: Intercomparison of the gas-phase chemistry in several chemistry and transport models, Atmos. Environ., 32, 693-709, 1998.

Li, J., Georgescu, M., Hyde, P., Mahalov, A., and Moustaoui, M.: Achieving accurate simulations of urban impacts on ozone at high resolution, Environ. Res. Lett., 9, 114019, doi:10.1088/1748-9326/9/11/114019, 2014.

Lidster, R. T., Hamilton, J. F., Lee, J. D., Lewis, A. C., Hopkins, J. R., Punjabi, S., Rickard, A. R., and Young, J. C.: The impact of monoaromatic hydrocarbons on $\mathrm{OH}$ reactivity in the coastal UK boundary layer and free troposphere, Atmos. Chem. Phys., 14, 6677-6693, doi:10.5194/acp-14-6677-2014, 2014.
Rickard, A., Young, J., Pilling, M., Jenkin. M., Pascoe, S., and Saunders S.: The Master Chemical Mechanism Version MCM v3.2, available at: http://mcm.leeds.ac.uk/MCMv3.2/, last access: 15 July 2015.

Sander, R., Kerkweg, A., Jöckel, P., and Lelieveld, J.: Technical note: The new comprehensive atmospheric chemistry module MECCA, Atmos. Chem. Phys., 5, 445-450, doi:10.5194/acp-5445-2005, 2005.

Saunders, S. M., Jenkin, M. E., Derwent, R. G., and Pilling, M. J.: Protocol for the development of the Master Chemical Mechanism, MCM v3 (Part A): tropospheric degradation of nonaromatic volatile organic compounds, Atmos. Chem. Phys., 3, 161-180, doi:10.5194/acp-3-161-2003, 2003.

Sillman, S.: The relation between ozone, $\mathrm{NO}_{x}$ and hydrocarbons in urban and polluted rural environments, Atmos. Environ., 33, 1821-1845, 1999.

Stevenson, D. S., Young, P. J., Naik, V., Lamarque, J.-F., Shindell, D. T., Voulgarakis, A., Skeie, R. B., Dalsoren, S. B., Myhre, G., Berntsen, T. K., Folberth, G. A., Rumbold, S. T., Collins, W. J., MacKenzie, I. A., Doherty, R. M., Zeng, G., van Noije, T. P. C., Strunk, A., Bergmann, D., CameronSmith, P., Plummer, D. A., Strode, S. A., Horowitz, L., Lee, Y. H., Szopa, S., Sudo, K., Nagashima, T., Josse, B., Cionni, I., Righi, M., Eyring, V., Conley, A., Bowman, K. W., Wild, O., and Archibald, A.: Tropospheric ozone changes, radiative forcing and attribution to emissions in the Atmospheric Chemistry and Climate Model Intercomparison Project (ACCMIP), Atmos. Chem. Phys., 13, 3063-3085, doi:10.5194/acp-13-3063-2013, 2013.

Stockwell, W. R., Middleton, P., Chang, J. S., and Tang, X.: The second generation regional acid deposition model chemical mechanism for regional air quality modeling, J. Geophys. Res., 95, 16343-16367, 1990.

Stockwell, W. R., Kirchner, F., Kuhn, M., and Seefeld, S.: A new mechanism for regional atmospheric chemistry modeling, J. Geophys. Res.-Atmos., 102, 25847-25879, 1997.

Watson, L. A., Shallcross, D. E., Utembe, S. R., and Jenkin, M. E.: A Common Representative Intermediates (CRI) mechanism for VOC degradation. Part 2: Gas phase mechanism reduction, Atmos. Environ., 42, 7196-7204, 2008.

Yarwood, G., Rao, S., Yocke, M., and Whitten, G. Z.: Updates to the Carbon Bond Chemical Mechanism: CB05, Tech. rep., US Environmental Protection Agency, Novato, California, USA, 2005. 